\title{
The Peculiarity of Lateral Preferences and the Quality of the Task Performance within the Go/Go Paradigm in Children with Complex Language Disabilities
}

\author{
Elena Ivanovna Nikolaeva ${ }^{1,2^{*}}$, Elvira Bronislavovna Dunaevskaya ${ }^{1}$, \\ Svetlana Nikolaevna Nikiforova ${ }^{1}$ \\ ${ }^{1}$ Department of Child Development and Family Pedagogics, Herzen State Pedagogical University, Saint Petersburg, \\ the Russian Federation \\ ${ }^{2}$ Department of Psychophysiolohy and Psychological Pedagogics, Bunin Yelets State University, Yelets, the Russian Federation \\ Email: *klemtina@yandex.ru
}

How to cite this paper: Nikolaeva, E. I., Dunaevskaya, E. B., \& Nikiforova, S. N. (2020). The Peculiarity of Lateral Preferences and the Quality of the Task Performance within the Go/Go Paradigm in Children with Complex Language Disabilities. Psychology, 11, 419-427.

https://doi.org/10.4236/psych.2020.113027

Received: December 17, 2019

Accepted: March 14, 2020

Published: March 17, 2020

Copyright (๑) 2020 by author(s) and Scientific Research Publishing Inc. This work is licensed under the Creative Commons Attribution International License (CC BY 4.0).

http://creativecommons.org/licenses/by/4.0/

\begin{abstract}
The present study has tested the hypothesis of the connection of speech problems in children with left-handedness with the realisation of some high-speed reactions, in particular, a simple sensorimotor reaction in the paradigm of go/go. The handedness is determined on the basis of a set of tests; their results correlate with the results of dichotic testing. The study involves 90 children without any speech disorders and 47 children with complex speech disturbances (CSD). It is shown that the children with CSD are more likely to be not left-handed but mixed-handed in comparison with children with no speech disorders. The probability of speech diagnosis is connected with the mother's age at birth and her level of education. The older the mother at birth is and the higher the level of her education is, the less likelihood of speech diagnosis is. The children without any CSD are more steady and better at performing the task in the go/go paradigm in comparison with the children with CSD. The stability of the task performance is associated with the age of the parents. The older the father and mother are, the more effective the child without any CSD during the second part of the task works.
\end{abstract}

\section{Keywords}

Children, Complex Speech Disturbances, Intellectual Disturbances, the Go/Go Paradigm, Handedness, Left-Handedness 


\section{Introduction}

At the present time, most investigators believe that severe speech disorders in children are the result of some causes during the development of the fetus or at birth (Davies, 2014). The fetus developing in the mother's womb is exposed to various impacts determined primarily by the influence of external conditions upon the mother. Such effects are described by the model of the instability of development. According to that, it is almost impossible for an external observer to trace little external influences which lead to various inconsistencies of the organs of the left and right sides of the body (one ear can be slightly longer, shorter or longer fingers, etc. (Yeo, Gangestad, \& Thoma, 2007).

Such features may be more common in those who have a changed language lateralization (Sandmann et al., 2007). It is supposed that the lateralization of speech is based on deeper mechanisms than those directly associated with speech (Fitch, Miller, \& Tallal, 1997). It is reckoned that the left hemisphere is responsible for the fast temporal processing (that is why the centre of speech is located in it), while the right hemisphere is responsible not for temporal but for the spectral constituents of information processing (Shtyrov, 2000; Poeppel, 2003).

The formation of speech zones in a child occurs long before he or she begins to learn to speak (Werker \& Tees, 1984). The EEG studies find that the both hemispheres are involved in the speech processing in children, although their role in this process is different (Segalowitz \& Cohen, 1989).

Functional neuroimaging studies indicate that the right and left upper temporal gyrases participate in the fundamental analysis of the spectral-temporal modulation regardless of the linguistic content of sounds (Meyer et al., 2005b; Specht et al., 2005). However, the hemispheres are involved in processing to a different extent (Meyer et al., 2005a; Rimol et al., 2005; Scott \& Wise, 2004).

Changes in the brain activation during the speech production are detected in children with language learning impairment (Tallal, 2004). The deficit is associated with the speed of the change of acoustic parameters (keys) in the speech signal that makes it difficult to identify the speech production (Tallal \& Gaab, 2006; Gordon-Salant et al., 2006). Difficulties associated with the temporal processing of speech information are connected with the asymmetry of the neuronal representations of speech (Bellis, Nicol, \& Kraus, 2000). The transcranial magnetic stimulation leads to the improvement of the state of children with linguistic impairments (Pinchuk et al., 2015) and changes in the lateralization of the brain structures: a greater activation of the left hemisphere during the processing of the speech signal. Diffusive tensor imaging tractography is used to describe the asymmetry of an arcuate fasciculus, a pathway that connects the temporal and inferior frontal language cortices (Glasser \& Rilling, 1991). It is supposed that the arcuate fasciculus consists of two segments with different functions: one terminates in the posterior superior temporal gyrus (STG), and another terminates in the middle temporal gyrus (MTG). It has turned out that the STG terminations are strongly left-lateralized and overlapped with phonological activations in the 
left but not the right hemisphere. One may suppose that only the left-hemisphere phonological cortex is directly connected with the frontal lobe via the arcuate fasciculus. The MTG terminations are also strongly left-lateralized overlapping with left-lateralized lexical-semantic activations. Smaller right-hemisphere MTG terminations overlap with right-lateralized prosodic activations.

At the same time, the variety of authors note reduction in the severity of the left-sided asymmetry for one reason or another during the certain speech disorders (Key et al., 2007; Kurth et al., 2018; Naoufal et al., 2016; Wilson \& Bishop, 2018). One of the most common causes associated with the growth of speech problems is called left-handedness (Nikolaeva et al., 1995).

Then, there is an evidence that the speech development is influenced by many parameters in the family, for example, the age of parents at birth, the number of children in the family and the order of a child birth. These factors are related to the fact that the older the parents, the more likely it is that the mother carries the child in a more comfortable environment, and immediately after birth, the child receives more support compared to the situation of a child birth in family with very young parents. The more children in the family, the fewer time parents spend communicating with each child. And the first child is more likely to receive maximum attention from adult family members (Nikolaeva, 1998; Nikolaeva, Goncharov, \& Borisenkova, 2017). That is why the purpose of this work was to identify the features of lateral preferences and efficiency of the simple sensorimotor response (the go/go paradigm) in children with speech disorders of different severity, taking into account the characteristics of the families in which they were raised.

\section{Materials and Methods}

\subsection{Subjects}

The study involved 90 children without any speech disturbances ( 45 boys and 45 girls, the mean age $5.6 \pm 0.8$ ) and 52 children with speech disturbances ( 28 boys and 24 girls, the mean age $5.8 \pm 0.7$ years). The children with speech problems were divided into two groups: 26 individuals ( 13 girls and 13 boys) had only complex speech disturbances (CSD), 26 children had speech disturbances combined with intellectual disturbances (CSD + ID) (13 boys and 13 girls).

The parents of all participants gave informed consent, and child participants provided informed assent.

\subsection{Methods}

1) The leading hand identification. To identify the handedness, the child was offered with the most common tests presented in the literature (Vergunov et al., 2018). Each test was performed three times. These included the following tests: the grip of the fingers, the pose of Napoleon and the shoulder test. The choice of the tests was stipulated by their efficiency: it was proved that their results correlate significantly with the results of dichotic testing (Nikolaeva \& Brisberg, 2018; Vergunov et al., 2018). 
Each result had a numerical value: if the test was performed in the left way-1, right -3 , the child changed the method of execution from time to time-2.

2) The evaluation of the efficiency of the simple sensorimotor response (the go/go paradigm) by means of a computer version of the Biofeedback response (Nikolaeva \& Borisenkova, 2009).

Circles of different colours were presented to the children on the computer at the same interval. According to the instruction, one should have pressed the enter key as quickly as possible when the circle appeared.

3) The parents of the children filled in the questionnaire in which they reported their age at birth, the level of education and the number of children in the family.

\section{Results}

First, regression analysis is carried out to determine which parameters of the parent questionnaire are in favour of the probability of the speech diagnosis in the child. Linear regression analysis was used in this work, which means that a negative beta value indicates an inverse correlation between variables. In this case, $\mathrm{R}$ square tells us how much variance in the dependent variable is explained by the independent variable.

Table 1 and Table 2 show that the probability of speech disturbances in the children depends upon the age of the mother at birth and the level of the mother's education. The younger she is, the more likely speech disorders are; and the higher education, the less likely speech disorders in the child are.

The distribution of the children according to the types of handedness is in Table 3.

Table 1. The influence of the independent variable "the mother's age" on dependent variables.

\begin{tabular}{cccc}
\hline Dependent variable & $\mathrm{R}^{2}$ & $\beta$ & $p$ \\
\hline Diagnosis & 0.171 & -0.412 & 0.000 \\
\hline
\end{tabular}

Table 2. The influence of the independent variable "the mother's education" on dependent variables.

\begin{tabular}{cccc}
\hline Dependent variable & $\mathrm{R}^{2}$ & $\beta$ & $p$ \\
\hline Diagnosis & 0.110 & -0.340 & 0.005 \\
\hline
\end{tabular}

Table 3. The distribution of the children according to the types of handedness (\%).

\begin{tabular}{cccc}
\hline Subjects & Left & Mixed & Right \\
\hline Norm & 14.0 & 71.4 & 14.6 \\
CSD & $0^{*}$ & $80.9^{*}$ & 19.1 \\
CSD + ID & $5.8^{*}$ & $89.0^{*}$ & $5.2^{*}$ \\
\hline
\end{tabular}

Note: ${ }^{*}=$ differences between the groups for $p \leq 0.05$ (Student's criterion). 
It shows that the group with speech disturbances and intellectual disability differs from the others in the number of the mixed-handed children and decrease in the number of the left-handed children. The children without any speech disturbances are right- and left-handed at the different probability, while the children with CSD and ID are likely to have mixed-handedness. Our data do not correspond to the idea that speech problems are typical of left-handed children.

Table 4 shows the result of the regression analysis which assesses the influence of independent variable of handedness. It has turned out that that parameter affects the speed of the response in this sample: the more right-handed the child is, the faster he responses in the simple sensorimotor reaction.

Table 5 shows the response speed and the number of omissions during the first and second series of the simple sensorimotor response. The first and second parts are identical. The healthy children perform the first part rather slowly making a small number of mistakes. Having understood the essence of the task, they perform it significantly faster and with a better quality. At the beginning, the children with CSD perform the task faster but with a large number of mistakes, and the quality of the execution has not changed over time. The children with the dual diagnosis are evidently tired by the end, and some have missed almost all the stimuli.

Table 6 and Table 7 show the results of regression analysis in the group of the children without any speech disorders. The influence of the age of the mother and father on the response speed of the child during the second part of the simple sensorimotor reaction has been identified.

In the both cases, the older the parent's age is, the more (as to the faster execution by the children of the whole group) the response time during the second part is. No similar results have been obtained for the children of the other two groups.

Table 4. The influence of the independent variable "handedness" on dependent variables in the children.

\begin{tabular}{cccc}
\hline Dependent variable & $\mathrm{R}^{2}$ & $\beta$ & $p$ \\
\hline Time of reaction & 0.254 & 0.502 & 0.005 \\
\hline
\end{tabular}

Table 5. Parameters of the simple sensorimotor reaction in the children.

\begin{tabular}{ccccc}
\hline Children & Omissions & $\begin{array}{c}\text { The mean time reaction, } \\
\text { part 1, mc }\end{array}$ & Omissions & $\begin{array}{c}\text { The mean time reaction, } \\
\text { part 2, mc }\end{array}$ \\
\hline Norm & $0.3 \pm 0.5$ & $489.7 \pm 192.1$ & $0.2 \pm 0.2$ & $360.2 \pm 141.8$ \\
CSD & $3.4 \pm 4.0^{* *}$ & $415.5 \pm 130.6$ & $3.2 \pm 3.7^{* *}$ & $408.2 \pm 182.6$ \\
CSD + ID & $2.2 \pm 3.5^{* *}$ & $527.5 \pm 201.6$ & $8.6 \pm 17.8^{* *}$ & $418.4 \pm 158.1$ \\
\hline
\end{tabular}

Note: * (see Table 3 ) the difference in the task performance by the children of the same group, $p \leq 0.05$. 
Table 6. The influence of the independent variable "mother's age" on dependent variables in norm.

\begin{tabular}{cccc}
\hline Dependent variable & $\mathrm{R}^{2}$ & $\beta$ & $p$ \\
\hline The mean time reaction, part two & 0.198 & 0.446 & 0.034 \\
\hline
\end{tabular}

Table 7. The influence on the independent variable "father's age" on dependent variables in norm.

\begin{tabular}{cccc}
\hline Dependent variables & $\mathrm{R}^{2}$ & $\beta$ & $p$ \\
\hline The mean time reaction, part two & 0.224 & 0.474 & 0.025 \\
\hline
\end{tabular}

\section{Discussion}

The study tested the hypothesis of the relationship of the speech problems of children with left-handedness and the performance of some high-speed reactions, in particular, the simple sensorimotor response in the paradigm of go/go.

When identifying the preferred hand, we used the tests that correlated with dichotic testing. Each test was repeated (not in a row but with a certain time interval) three times to avoid any incidental execution. Our data indicated that among the children with speech problems, the number of the left-handers was even less than in the group without any speech problems. At the same time, in that group, the number of children with the mixed handedness increases, that is, they perform different tests by different hands. Our data confirm the idea of that central asymmetry (hemispheric asymmetry) is not directly connected to lateral preferences, i.e. peripheral asymmetry.

The obtained data indicate that the likelihood of the diagnosis depends on the mother's age at birth and her level of education. We may assume that this is due to the following. During the first year of life, the child's brain is extremely flexible, and therefore, the activity and adequate actions of the mother can lead to the rehabilitation of the processes disturbed during the pregnancy or childbirth. The older the mother, the more carefully she prepares for pregnancy, the more adequately during the pregnancy toward the needs of the child she behaves and prepares for childbirth, and the more attentive she is to the problems of the child immediately after birth. The higher the mother's education, the more she reads the necessary literature, the oftener in case of some problems in the child she consults specialists and carefully follows the instructions. All this leads to a quality care of the child and decrease the likelihood of speech problems.

In the norm group, we have also found associations between the parents' age and the response speed of the child's during the second part of the task. One may suppose that the older the parents, the more attention they pay to the discipline of the child and the arrangement of his/her activity. Therefore, the child is more effective in the second part of the task and more attentive when children from the other two groups are tired. 


\section{Conclusion}

Children with speech problems are often not left-handed but mixed-handed in comparison with children without any speech disturbances. The probability of a speech diagnosis is connected with the mother's age at birth and her level of education. The older the mother is at birth, and the higher the level of her education is, the less likelihood of a speech diagnosis. Children without any speech diagnosis are more steady and better at the task performance in the go/go paradigm in comparison with children with the speech diagnosis. The stability of the work during the second part of the task is associated with the age of the parents. The older the father and mother, the more efficient the child works during the second part of the work (when most other children are tired).

\section{Ethical Approval}

All procedures performed in studies involving human participants were in accordance with the ethical standards of the Institutional and/or National Research Committee and with the1964 Helsinki Declaration and its later amendments or comparable ethical standards.

\section{Limitations and Future Directions}

One primary limitation of the current investigation was a size of groups of children with speech problems. Perhaps increasing the sample would lead to differences in lateral preferences between children with speech disorders of varying severity. We think that children with more pronounced speech disorders will have more left-sided preferences than children with less pronounced speech disorders.

The second limitation is the used method. We have used go/go paradigm, but we sure that more interesting results could be in go/no-go paradigm since children with more pronounced speech disorders may have unformed inhibitory control. Now we are beginning this type of research.

\section{Fundings}

The present work is supported by the Russian Fundamental Research Fund, project \#18-013-00323 A.

\section{Conflicts of Interest}

The authors declare no conflicts of interest regarding the publication of this paper.

\section{References}

Bellis, T. J., Nicol, T., \& Kraus, N. (2000). Aging Affects Hemispheric Asymmetry in the Neural Representation of speech Sounds. Journal of Neuroscience, 20, 791-797. https://doi.org/10.1523/JNEUROSCI.20-02-00791.2000

Davies, J. A. (2014). Life Unfolding. How the Human Body Creates Itself. Oxford: Oxford University Press. 
Fitch, R. H., Miller, S., \& Tallal, P. (1997). Neurobiology of Speech Perception. Annual Review of Neuroscience, 20, 331-353. https://doi.org/10.1146/annurev.neuro.20.1.331

Glasser, M. F., \& Rilling, J. K. (1991). DTI Tractography of the Human Brain's Language Pathways. Cerebral Cortex, 8, 2471-2482. https://doi.org/10.1093/cercor/bhn011

Gordon-Salant, S., Yeni-Komshian, G. H., Fitzgibbons, P. J., \& Barrett, J. (2006). Age-Related Differences in Identification and Discrimination of Temporal Cues in Speech Segments. The Journal of the Acoustical Society of America, 119, 2455-2466. https://doi.org/10.1121/1.2171527

Key, A. P. F., Ferguson, M., Molfese, D. L., Peach, K., Lehman, C., \& Molfese, V. (2007). Smoking during Pregnancy Affects Speech-Processing Ability in Newborn Infants. Environmental Health Perspectives, 115, 623-628. https://doi.org/10.1289/ehp.9521

Kurth, F., Luders, E., Pigdon, L., Conti-Ramsden, G., Reilly, S., \& Morgan, A. T. (2018). Altered Gray Matter Volumes in Language-Associated Regions in Children with Developmental Language Disorder and Speech Sound Disorder. Developmental Psychobiology, 60, 814-824. https://doi.org/10.1002/dev.21762

Meyer, M., Zaehle, T., Gountouna, V. E., Barron, A., Jancke, L., \& Turk, A. (2005a). Spectro-Temporal Processing during Speech Perception Involves Left Posterior Auditory Cortex. Neuroreport, 16, 1985-1989. https://doi.org/10.1097/00001756-200512190-00003

Meyer, M., Zysset, S., von Cramon, D. Y., \& Alter, K. (2005b). Distinct fMRI Responses to Laughter, Speech, and Sounds along the Human Perisylvian Cortex. Brain Research. Cognitive Brain Research, 24, 291-306. https://doi.org/10.1016/j.cogbrainres.2005.02.008

Naoufal, R., Legendre, M., Couet, D., Gilbert-Dussardier, B., Kitzis, A., Bilan, F., \& Harbuz, R. (2016). Association of Structural and Numerical Anomalies of Chromosome 22 in a Patient with Syndromic Intellectual Disability. European Journal of Medical Genetics, 59, 483-487. https://doi.org/10.1016/j.ejmg.2016.07.001

Nikolaeva, E. I. (1998). Intellectual Peculiarities of Boys and Girls with Different Laterality Indices. International Journal of Psychophysiology, 30, 219. https://doi.org/10.1016/S0167-8760(98)90573-6

Nikolaeva, E. I., \& Borisenkova, E. Yu. (2009). The Severity of Lateral Signs in Preschool Children with Different Levels of Intelligence. Psychological Journal, 30, 47-55.

Nikolaeva, E. I., \& Brisberg, T. L. (2018). Tests Aimed at the Evaluating the Connections of the Leading Hand with the Results of Dichotic Test. Asymmetry, 12, 350-359.

Nikolaeva, E. I., Goncharov, D. A., \& Borisenkova, E. Yu. (2017). Connection of the Intellect of a School-Age Child with the Age and Level of Education of Parents at His Birth. Bulletin of Psychophysiology, 3, 51-55.

Nikolaeva, E. I., Otieva, E. A., Maslennikov, A. B., Nikolaeva, A. A., Leutin, V. P., \& Osipova, L. P. (1995). Relationships between the Left Hemisphere Predominance and the Disturbances of Lipid Metabolism in the Different Ethnic Groups. International Journal of Cardiology, 52, 207-211. https://doi.org/10.1016/0167-5273(95)02465-4

Pinchuk, D. Y., Wasserman, M. V., Wasserman, E. L., Sirbiladze, K. T., \& Kartashev, N. K. (2015). Effect of Transcranial Direct Current Stimulation on Dichotic Listening Test Results in Children with Disorders of Psychological Development. Polish Annals of Medicine, 22, 67-73. https://doi.org/10.1016/j.poamed.2015.05.005

Poeppel, D. (2003). The Analysis of Speech in Different Temporal Integration Windows: Cerebral Lateralization as "Asymmetric Sampling in Time". Speech Communication, 41, 245-255. https://doi.org/10.1016/S0167-6393(02)00107-3 
Rimol, L. M., Specht, K., Weis, S., Savoy, R., \& Hugdahl, K. (2005). Processing of Sub-Syllabic Speech Units in the Posterior Temporal Lobe: An fMRI Study. Neuroimage, 26, 1059-1067. https://doi.org/10.1016/j.neuroimage.2005.03.028

Sandmann, P., Eichele, T., Specht, K., Jäncke, L., Rimol, L. M., Nordby, H., \& Hugdahl, K. (2007). Hemispheric Asymmetries in the Processing of Temporal Acoustic Cues in Consonant-Vowel Syllables. Restorative Neurology \& Neuroscience, 25, 227-240.

Scott, S. K., \& Wise, R. J. S. (2004). The Functional Neuroanatomy of Prelexical Processing in Speech Perception. Cognition, 92, 13-45. https://doi.org/10.1016/j.cognition.2002.12.002

Segalowitz, S. J., \& Cohen, H. (1989). Right Hemisphere EEG Sensitivity to Speech. Brain Lang, 37, 220-231. https://doi.org/10.1016/0093-934X(89)90016-3

Shtyrov, Y. (2000). Auditory Cortex Evoked Magnetic Fields and Lateralization of Speech Processing. Neuroreport, 11, 2893-2896. https://doi.org/10.1097/00001756-200009110-00013

Specht, K., Rimol, L. M., Reul, J., \& Hugdahl, K. (2005). "Soundmorphing”: A New Approach to Studying Speech Perception in Humans. Neuroscience Letters, 384, 60-65. https://doi.org/10.1016/j.neulet.2005.04.057

Tallal, P. (2004). Improving Language and Literacy Is a Matter of Time. Nature Reviews Neuroscience, 5, 721-728. https://doi.org/10.1038/nrn1499

Tallal, P., \& Gaab, N. (2006). Dynamic Auditory Processing, Musical Experience and Language Development. Trends in Neurosciences, 29, 382-390. https://doi.org/10.1016/j.tins.2006.06.003

Vergunov, E. G., Nikolaeva, E. I., Balioz, N. V., \& Krivoschekov, S. G. (2018). Lateral Preferences as the Possible Phenotypic Predictors of the Reserves of the Cardiovascular System and the Features of Sensorimotor Integration in Climbers. Human Physiology, 44, 320-329. https://doi.org/10.1134/S0362119718030143

Werker, J. F., \& Tees, R. C. (1984). Phonemic and Phonetic Factors in Adult Cross-Language Speech Perception. The Journal of the Acoustical Society of America, 75, 1866-1878. https://doi.org/10.1121/1.390988

Wilson, A. C., \& Bishop, D. V. M. (2018). Sex Chromosome Trisomies Are Not Associated with Atypical Lateralization for Language. Developmental Medicine \& Child Neurology, 60, 1132-1139. https://doi.org/10.1111/dmcn.13929

Yeo, R. A., Gangestad, S. W., \& Thoma, R. J. (2007). Developmental Instability and Individual Variation in Brain Development: Implications for the Origin of Neurodevelopmental Disorders. Current Directions in Psychological Science, 16, 245-249.

https://doi.org/10.1111/j.1467-8721.2007.00513.x 